\title{
Produção de Forragem e Produção Animal em Pastagem com Duas Disponibilidades de Forragem Associadas ou não à Suplementação Energética
}

\author{
Alcides Pilau1, Marta Gomes da Rocha ${ }^{2}$, João Restle ${ }^{3}$, Fabiana Kellermann de Freitas ${ }^{4}$, Dalton Roso ${ }^{5}$
}

\begin{abstract}
RESUMO - Neste experimento, avaliou-se o efeito de duas disponibilidades de forragem, 1.200 e $1.500 \mathrm{~kg} / \mathrm{ha} \mathrm{de} \mathrm{matéria} \mathrm{seca} \mathrm{(MS),}$ e do uso de suplementação energética sobre a produção de forragem e a produção animal em pastagem de aveia (Avena strigosa Schreb) + azevém (Lolium multiflorum Lam). Foram utilizadas 90 novilhas da raça Charolês e suas cruzas com Nelore, com peso vivo (PV) de $164 \mathrm{~kg}$ no início do pastejo, submetidas às seguintes combinações: DFB - disponibilidade de forragem baixa; DFA - disponibilidade de forragem alta; DFBS - disponibilidade de forragem baixa + suplementação energética; DFAS - disponibilidade de forragem alta + suplementação energética. O suplemento fornecido foi grão de sorgo moído, na proporção de $0,7 \%$ do PV. As variáveis estudadas foram produção de forragem (PF), carga animal (CA) e ganho de peso vivo por área (GPA). A PF não foi influenciada pelo manejo da pastagem e pela suplementação aos animais. O acúmulo de forragem diário estimado foi de $45,53 \mathrm{~kg} / \mathrm{ha}$ de MS. A CA na DFA, média de $862 \mathrm{~kg} /$ ha de PV, apresentou pouca variação no decorrer do ciclo de pastejo. Em DFAS, DFB e DFBS, a carga animal foi extremamente variável e, a partir de 26/08, foi maior na DFBS. A utilização de $1.200 \mathrm{~kg} /$ ha de MS não afetou o GPA, enquanto a suplementação aos animais proporcionou aumento de $59,4 \%$ em relação ao uso exclusivo da pastagem.
\end{abstract}

Palavras-chave: Avena strigosa, grão de sorgo, Lolium multiflorum, pastejo contínuo

\section{Effects of Forage Availability and Energy Supplementation on Herbage Accumulation Rate and Animal Yield}

\begin{abstract}
The trial was conducted to evaluate two forage availabilities (1.200 and $1.500 \mathrm{~kg} / \mathrm{ha}$ of dry matter [DM]) and energy supplementation of winter pasture on herbage and animal yields. The pasture was a mixture of oat (Avena strigosa Schreb) + Italian ryegrass (Lolium multiflorum Lam). Ninety Charolais and Charolais crossbred Nellore heifers, with initial live weight of $164 \mathrm{~kg}$, were submitted to the following treatments: LFA - low forage availability; HFA - high forage availability; LFAS - low forage availability + supplementation; HFAS - high forage availability + supplementation. The daily supplementation of ground sorghum corresponded to $0.7 \%$ body weight (BW). The variables studied were forage accumulation rate (FAR), stocking rate (SR) and live weight gain (LWG). Forage availability and supplementation did not affect FAR, which averaged $45.53 \mathrm{~kg} / \mathrm{ha}$ DM. The average SR in DFA, $862 \mathrm{~kg} / \mathrm{ha}$ of BW, was quite constant during pasture grazing cycle. The SR was extremely variable in LFAS, HFA and LFAS treatments, being greatest in LFAS treatment after 08/26. Body weight gain per hectare was not affected by forage availability but increased by $59.4 \%$ in response to pasture supplementation.
\end{abstract}

Key Words: Avena strigosa, sorghum grain, Lolium multiflorum, continuous grazing

\section{Introdução}

A utilização de pastagens cultivadas, para ser lucrativa, deve ser otimizada considerando-se a categoria animal em pastejo. Diferentes categorias animais interferem na eficiência de utilização da pastagem de inverno (Restle et al., 1998) e, ao incrementar consideravelmente a carga animal, com alta intensidade de pastejo, o desafio é manter o máximo consumo pelos animais, assegurando desempenho individual satisfatório.
O manejo alimentar das novilhas têm grande impacto sobre a composição do rebanho e, conseqüentemente, sobre a utilização da área pastoril da propriedade. Quando existe a utilização de pastagens de inverno, a taxa de lotação a ser aplicada é dependente da velocidade de crescimento desejada para estas novilhas e da área disponível para a recria destes animais. As pastagens podem ser manejadas para ganhos de peso individuais moderados e maior carga animal (Beretta \& Lobato, 1998; Rocha et al., 2003a) ou buscando-se maior desempenho individual das novilhas (Frizzo et al., 2003).

\footnotetext{
1 Zoot. Aluno do programa de Pós-Graduação em Zootecnia- UFSM. Bolsista CAPES (alcidespilau@bol.com.br).

2 Eng. Agr. Dra .Bolsista CNPq. Prof ${ }^{a}$. Adjunta do Departamento de Zootecnia - UFSM (tata@via-rs.net).

${ }^{3}$ Eng. Agr. PhD, Professor Titular do Departamento de Zootecnia, UFSM (jorestle@ccr.ufsm.br).

4 Eng. Agr. Aluna do Programa de Pós-Graduação em Zootecnia - UFSM (fkfreitas@hotmail.com).

${ }^{5}$ Aluno do curso de Graduação em Agronomia UFSM. Bolsista Fapergs.
} 
O potencial da pastagem é representado pela quantidade e qualidade de forragem que é capaz de produzir. A disponibilidade e a qualidade da forragem, por sua vez, são influenciadas pela espécie forrageira, pelas propriedades do solo, condições climáticas, pela idade fisiológica e pelo manejo a que está submetida. $\mathrm{O}$ aumento na disponibilidade incrementa a capacidade fotossintética da pastagem, graças à maior área foliar e interceptação da luz e, como conseqüência, eleva o crescimento e a produção de forragem. Em disponibilidades excessivamente altas, no entanto, a produção diminui, em virtude do aumento no percentual de material morto presente. A redução na quantidade de forragem disponível pode provocar declínio na performance animal, em razão da menor oportunidade de pastejo seletivo (Philips, 1988). O ideal seria desenvolver estruturas de pastagem que permitissem manter alto consumo pelos animais associado à pequena altura da forragem residual.

No manejo de pastagens, é importante que exista habilidade para evitar a redução excessiva da massa de forragem, pois condições climáticas variáveis podem conduzir a um encurtamento do ciclo produtivo pela inexistência de índice de área foliar adequado para rebrota. Quando as condições climáticas são desfavoráveis, a suplementação é uma prática de baixo risco e que de forma efetiva, pode conduzir à manutenção de índices de produção consideráveis, sobretudo em sistemas pecuários de ciclo completo.

A eficiência do uso da suplementação é dependente do efeito do consumo de suplemento sobre o de forragem. Dois fatores afetam a ingestão de nutrientes quando bovinos em pastejo são suplementados com concentrado: a taxa de substituição da forragem por concentrado e a queda da digestão de fibra. Em pastagem de alta qualidade, como aveia (Avena strigosa Schreb) e azevém (Lolium multiflorum Lam), o efeito da suplementação sobre a taxa de substituição é mais importante que sobre a digestão da fibra. Como a digestão da fibra pode ser pouco alterada, a suplementação concentrada pode possibilitar o aumento no suprimento de nutrientes sem redução na utilização da forragem (Rearte \& Pieroni, 2001).

Os benefícios diretos da utilização da suplementação energética para novilhas em recria sobre pastagem de aveia e azevém são os acréscimos em desempenho individual e/ou carga animal. A suplementação, indiretamente, possibilita a liberação antecipada da área para outras categorias e melhor utilização da área pastoril como um todo, considerando o ciclo completo. O sucesso de sua utilização, entretanto, depende da maximização do uso do suplemento, em função do seu custo de aquisição (Pilau et al., 2003).

A hipótese testada neste experimento foi a de que, em menor disponibilidade de forragem, a suplementação assegurasse estabilidade na carga animal sem prejudicar a produção de forragem, refletindo diretamente sobre o ganho de peso por área. Avaliou-se a produção animal e a de forragem sob duas disponibilidades de forragem, 1.200 e $1.500 \mathrm{~kg} / \mathrm{ha}$ de MS, associadas ou não à suplementação energética.

\section{Material e Métodos}

O experimento foi conduzido em área pertencente ao Departamento de Zootecnia da Universidade Federal de Santa Maria (UFSM), localizada na Depressão Central do Rio Grande do Sul, com altitude de $95 \mathrm{~m}$, latitude 2943' Sul e longitude 5342' Oeste.

$\mathrm{O}$ solo da área experimental pertence à unidade de mapeamento São Pedro, é classificado como Argissolo Vermelho Distrófico Arênico (EMBRAPA, 1999) e apresenta relevo levemente ondulado, com solos profundos e de textura superficial arenosa, bem drenados e naturalmente ácidos. O clima da região é Cfa (subtropical úmido), conforme classificação de Köppen (Moreno, 1961).

A temperatura, insolação e precipitação médias verificadas nos meses de maio a novembro de 2001 e as normais dos últimos 30 anos registradas pelo centro de meteorologia da UFSM, foram 17,4 e $16,2^{\circ} \mathrm{C}, 162,8$ e 166,0 horas, 142,9 e $141,5 \mathrm{~mm}$, respectivamente. A área experimental foi dividida em 12 piquetes, com área média de 0,97 ha, totalizando 11,7 ha e uma área contígua de 4,6 ha para permanência dos animais reguladores.

A pastagem foi implantada pelo sistema de plantio direto, no dia 15 de maio de 2001. Na dessecação da área, foram aplicados dois $\mathrm{L} /$ ha do herbicida glifosato. Foram utilizados, na semeadura, $90 \mathrm{~kg} / \mathrm{ha}$ de aveia preta, $35 \mathrm{~kg} / \mathrm{ha}$ de azevém e $300 \mathrm{~kg} / \mathrm{ha}$ de adubo da fórmula 05-20-20. Em cobertura, foram distribuídos $170 \mathrm{~kg} /$ ha de nitrogênio $(\mathrm{N})$, na forma de uréia, em quatro aplicações.

O período de estabelecimento da pastagem foi de 45 dias e o método de pastejo foi contínuo, utilizandose três animais teste e um número variável de reguladores por repetição. Os animais utilizados foram 90 
novilhas com idade inicial média de oito meses, pertencentes ao setor de Bovinocultura de Corte. Os animais-teste, formados pelos grupos genéticos Charolês, 3/4 Charolês/Nelore e 5/8 Charolês/Nelore, apresentaram peso vivo no início do pastejo, em média, de $164 \mathrm{~kg}$.

O desempenho produtivo foi avaliado com animais em pastejo sob duas disponibilidades de forragem, com ou sem o uso de suplementação energética. As combinações foram: DFB - disponibilidade de forragem baixa; DFA - disponibilidade de forragem alta; DFBS - disponibilidade de forragem baixa + suplementação energética; DFAS - disponibilidade de forragem alta + suplementação energética.

As disponibilidades de forragem baixa e alta pretendidas foram de $1.200 \mathrm{e} 1.500 \mathrm{~kg} / \mathrm{ha}$ de matéria seca (MS), respectivamente. No decorrer do período de pastejo, procurou-se manter uma diferença superior a $200 \mathrm{~kg} / \mathrm{ha}$ de MS entre as duas disponibilidades. O suplemento utilizado foi grão de sorgo moído na proporção de $0,7 \%$ do peso vivo, fornecido diariamente às $14 \mathrm{~h}$.

A massa de forragem (MF) foi determinada no início do período de pastejo e, posteriormente, a cada 14 dias pela técnica de dupla amostragem (Wilm et al., 1944). Em cada repetição, foram realizados cinco cortes rente ao solo e 20 estimativas visuais. Para determinação da taxa de acúmulo de forragem (TAD), foram utilizadas três gaiolas de exclusão ao pastejo por repetição, conforme metodologia descrita por Klingmann et al. (1943).

A adequação de carga animal (CA) para manter as disponibilidades de forragem desejadas foi realizada considerando-se o desaparecimento de forragem (consumo estimado + perdas de forragem), cujos valores variaram de 3 a 4,5\% do PV no início e ao final do ciclo da pastagem: $\mathrm{CA}=(\mathrm{TAD}+(\mathrm{MF}$ pretendidaMF atual)*100/(consumo estimado+ perdas de forragem). O consumo estimado foi de $2,5 \%$ do PV, valor recomendado pelo National Research Council - NRC (1984) para a categoria de fêmeas em recria, dos sete aos 12 meses de idade. Para determinação das perdas de forragem, foram demarcados, com estacas, oito pontos amostrais alocados em três transectas em cada repetição. Em cada ponto amostral, foi colocado um quadrado com área de $0,0625 \mathrm{~m}^{2}$ para coleta da forragem considerada como não aproveitável pelos animais - material morto, senescente e danificado pelo pisoteio e pastejo (Hillesheim, 1997).
As pesagens dos animais foram realizadas no início do período de pastejo e posteriormente a cada 28 dias, exceto no período final, que foi de 21 dias. As novilhas foram pesadas individualmente, após jejum de 12 horas. O controle de endoparasitas foi feito em duas dosificações dos animais com levamisol fosfato: a primeira 24 horas antes do início do período de pastejo e a segunda, em 22/09/2001.

O ganho de peso médio diário (GMD) dos animais foi obtido pela diferença entre peso final e inicial dos animais testes, em cada período experimental, dividido pelo número de dias do período. A carga animal (CA) por período foi obtida pela soma do peso médio dos animais-teste, acrescentando-se a este valor o peso médio dos animais reguladores multiplicado pelo número de dias nos quais estes permaneceram na repetição. O valor encontrado foi dividido pelo período de pastejo e expresso em $\mathrm{kg} /$ ha de $\mathrm{PV}$. O ganho de peso por área (GPA) foi obtido pelo somatório do ganho de peso dos animais-teste, adicionado-se o produto entre o GMD da repetição e o número de dias que cada animal regulador permaneceu no piquete.

O delineamento experimental foi o inteiramente casualizado em arranjo fatorial 2 x 2, com cada combinação formada por três repetições. Nas repetições, foram tomados dados de três unidades amostrais (animais testes).

O modelo matemático referente à análise dos parâmetros estimados foi:

$$
\begin{gathered}
\mathrm{Y}_{\mathrm{ijkl}}=\mu+\mathrm{D}_{\mathrm{i}}+\mathrm{S}_{\mathrm{j}}+(\mathrm{D} * \mathrm{~S})_{\mathrm{ij}}+\mathrm{R}_{\mathrm{k}}(\mathrm{D} * \mathrm{~S})_{\mathrm{ij}}+\mathrm{P}_{1} \\
+(\mathrm{D} * \mathrm{P})_{\mathrm{il}}+(\mathrm{S} * \mathrm{P})_{\mathrm{j} 1}+(\mathrm{D} * \mathrm{~S} * \mathrm{P})_{\mathrm{ijl}}+\mathrm{E}_{\mathrm{ijk}}
\end{gathered}
$$

em que $Y_{i j k l}=$ variáveis dependentes; $\mu=$ média de todas as observações; $\mathrm{D}_{\mathrm{i}}=$ efeito da i-ésima disponibilidade; $S_{j}=$ efeito da j-ésima suplementação; $D * S_{i j}$ $=$ efeito de interação entre a i-ésima disponibilidade $\mathrm{e}$ a j-ésima suplementação; $R_{k}(D * S)_{i j}=$ efeito da késima repetição dentro da interação entre a i-ésima disponibilidade e a j-ésima suplementação (erro A); $\mathrm{P}_{1}$ $=$ efeito do l-ésimo período; $\mathrm{D}^{*} \mathrm{P}_{\mathrm{il}}=$ efeito de interação entre a i-ésima disponibilidade e o l-ésimo período; $\mathrm{S} * \mathrm{P}_{\mathrm{j} 1}=$ efeito de interação entre a j-ésima suplementação e o l-ésimo período; $\mathrm{D} * \mathrm{~S} * \mathrm{P}_{\mathrm{ijl}}=$ efeito de interação entre a i-ésima disponibilidade, a j-ésima suplementação e o l-ésimo período; $\mathrm{E}_{\mathrm{ijk}}=$ erro residual (erro B).

As variáveis estudadas foram submetidas à análise de variância dos dados e o teste $\mathrm{F}$ a $5 \%$ de 
significância e, quando detectadas diferenças entre disponibilidade (D), suplementação (S) ou período (P), foram realizadas comparações de médias pelo teste Tukey a $5 \%$ de significância. O efeito da variável $\mathrm{D}$, neste caso, passou a ser representado apenas por DFA e DFB e o efeito da variável S, por Past e Past + supl. As variáveis que apresentaram interação $\mathrm{D} * \mathrm{P}$ e/ou $\mathrm{S} * \mathrm{P}$ foram submetidas ao teste de regressão polinomial até terceira ordem a $5 \%$, considerando -se a de maior coeficiente de determinação $\left(\mathrm{R}^{2}\right)$. As análises foram efetuadas pelo procedimento GLM (General Linear Models) do programa estatístico SAS versão 6.08 (SAS, 1996).

\section{Resultados e Discussão}

Não houve interação DF*SUPL $(\mathrm{P}>0,05)$ sobre a variável massa de forragem (MF) nos períodos de pastejo. O manejo da pastagem partiu de uma MF semelhante para todos os tratamentos, $837 \mathrm{~kg} / \mathrm{ha}$ de MS. A MF na DFB foi inferior à de DFA no final do primeiro período de pastejo $(\mathrm{P}<0,01), 1078$ e $1468 \mathrm{~kg} /$ ha de MS, respectivamente. Na média deste período, no entanto, não houve diferença significativa para esta variável, como conseqüência da mesma MF inicial. A estrutura da pastagem, nesta ocasião, foi bastante modificada na DFB, com visível aumento no número de perfilhos, tornando distintas as $\mathrm{MF}$ em DFB e DFA nos períodos subseqüentes $(\mathrm{P}<0,01)$.
No decorrer do período de pastejo, a MF média das disponibilidades de forragem foi elevada de $1.150 \mathrm{~kg} / \mathrm{ha}$ de MS, no primeiro, até $1.434 \mathrm{~kg} / \mathrm{ha}$ de MS no quarto período, como resultado, principalmente, do aumento no teor de MS da pastagem. Torna-se importante nesta situação manter altura mínima de forragem residual sem que haja impedimento ao pastejo seletivo pelos animais. No último período de pastejo, a maior senescência provocada pelo final do ciclo vegetativo do azevém resultou em diminuição na MF média para $1.322 \mathrm{~kg} / \mathrm{ha}$ de MS. Do ponto de vista prático, em áreas de integração lavoura-pecuária, a massa de forragem residual baixa ao final do pastejo pode comprometer a eficiência de produção da cultura subseqüente, quando utilizado o sistema de plantio direto. $\mathrm{Na}$ DFB, a MF residual foi de $1.226 \mathrm{~kg} /$ ha de MS, enquanto, na DFA, foi de $1.515 \mathrm{~kg} / \mathrm{ha}$ de MS, com visível maior área de solo descoberto na DFB.

A produção de forragem (PF) não foi influenciada pelo manejo distinto da pastagem ou pelo uso da suplementação aos animais $(\mathrm{P}>0,05)$ (Figura 1). No decorrer do período, a PF acumulada se ajustou melhor à regressão linear $(\hat{\mathrm{Y}}=1121,16+45,53 \mathrm{x}$; $\left.\mathrm{R}^{2}=0,87\right)$. $\mathrm{O}$ acúmulo de forragem diário estimado pela equação foi de $45,53 \mathrm{~kg} / \mathrm{ha}$ de MS.

A baixa oscilação na PF no decorrer do ciclo da pastagem, possibilita que a taxa de lotação varie muito pouco, minimizando a entrada e saída de animais da pastagem e reduzindo o manejo animal. Em propriedades rurais, a resposta linear na PF e o conhecimento

Tabela 1 - Massa de forragem (kg/ha de MS) em pastagem de aveia preta $(A$. strigosa) + azevém ( $L$. multiflorum) em duas disponibilidades de forragem, com ou sem suplementação

Table 1 - Forage mass ( $\mathrm{kg} / \mathrm{ha}$ DM) on oat (A. strigosa) + Italian ryegrass (L.multiflorum) pasture with two forage availability with or without supplementation

\begin{tabular}{lcccccc}
\hline $\begin{array}{l}\text { Tratamento } \\
\text { Treatment }\end{array}$ & \multicolumn{5}{c}{$\begin{array}{c}\text { Período } \\
\text { Period }\end{array}$} & $\begin{array}{c}\text { Média } \\
\text { Mean }\end{array}$ \\
\cline { 2 - 6 } & $01 / 07-28 / 07$ & $29 / 07-25 / 08$ & $26 / 08-22 / 09$ & $23 / 09-20 / 10$ & $21 / 10-09 / 11$ & $1447^{* *}$ \\
\hline DFA & 1233 & $1443^{* *}$ & $1512^{* *}$ & $1610^{* *}$ & $1448^{* *}$ & $1174^{* *}$ \\
DFB & 1067 & $1148^{* *}$ & $1201^{* *}$ & $1258^{* *}$ & $1196^{* *}$ & 1324 \\
\hline Past & 1200 & 1322 & 1381 & 1412 & 1313 & 1331 \\
Past+supl. & 1100 & 1269 & 1310 & 1456 & 133 \\
\hline Média & $1150 \mathrm{c}$ & $1296 \mathrm{~b}$ & $1343 \mathrm{ab}$ & $1434 \mathrm{a}$ & $1322 \mathrm{~b}$ & 1308 \\
Mean & & & & & 5,6 & 6,06 \\
\hline $\mathrm{CV}$ & 11,64 & 9,95 & 9,88 & 8,14 & 5,6 \\
\hline
\end{tabular}

** na mesma coluna, diferem entre si $(P<0,01)$ (in the same column, differ $[P<0.01])$.

$a, b$ na mesma linha diferem entre si $(P<0,01)(a, b$ in the same column, differ $[P<0.01])$.

DFA - disponibilidade de forragem alta, $1.500 \mathrm{~kg} / \mathrm{ha}$ de MS (DFA - high forage availability, 1,500 kg/ha DM).

DFB - disponibilidade de forragem baixa, $1.200 \mathrm{~kg} / \mathrm{ha}$ de MS (DFB - low forage availability, 1,200 kg/haDM).

Past - aveia preta + azevém sem suplementação (Past - oat + annual ryegrass without supplement).

Past + supl - aveia preta + azevém $+0,7 \%$ do PV de grão de sorgo moído (Past + suppl - oat + annual ryegrass $+0.7 \%$ LW sorghum grain) 


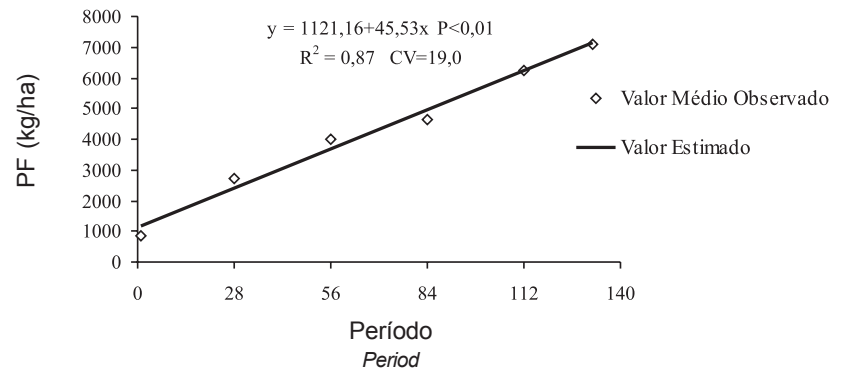

01/07-28/07 29/07-25/08 26/08-22/09 23/09-20/10 21/10-09/11

Figura 1 - Produção de forragem (PF) da pastagem de aveia ( $A$. strigosa) + azevém ( $L$. multiflorum) durante o período de pastejo com novilhas de corte em recria.

Figure 1 - Herbage accumulation rate (PF) of oat ( $A$. strigosa) + Italian ryegrass (L. multiflorum) pasture during the grazing period for rearing beef heifers.

do GMD pretendido permitiriam planejar o número de animais a ser mantido em determinada área, considerando-se o manejo utilizado e período de pastejo previsto. A avaliação prévia de alternativas para aumento na produção de forragem é fundamental para os sucessos biológico e econômico da utilização da pastagem de aveia e azevém em diferentes sistemas de produção, pois sua utilização mais intensiva tem sido questionada quanto à viabilidade econômica. Muitos produtoresque utilizaram altatecnologiadesistiram desta prática, sob a alegação de que o preço dos fertilizantes eleva-se em proporções maiores que o dos produtos agropecuários (Aguiar, 1999). O aumento da produtividade, entretanto, depende mais de fatores ligados ao manejo da pastagem que do custo de produção propriamente dito. Na Depressão Central do Rio Grande do Sul, no período de 1996 a 2001, foram verificadas, em pastagem de aveia preta + azevém, taxas de acúmulo médio diário de forragem de 40 a $50 \mathrm{~kg} / \mathrm{ha}$ de MS, em experimentos conduzidos em anos consecutivos em uma mesma área com novilhas de corte sob pastejo contínuo (Soares \& Restle, 2002; Roso et al., 2000; Frizzo et al., 2003; Freitas et al., 2002; Rocha et al., 2003a; Rocha et al., 2003b), valor semelhante ao obtido neste trabalho.

Planejamentos forrageiros envolvendo análises biológicas e econômicas são de difícil de implementação sem o uso adequado do ajuste de carga animal (CA) dentro do período de pastejo. A carga animal (Figura 2) sofreu efeito da interação entre disponibilidade de forragem, suplementação e período avaliado.

$\mathrm{Na}$ DFA, a CA não se ajustou às equações de regressão testadas, com média de $862 \mathrm{~kg} / \mathrm{ha}$ de $\mathrm{PV}$. Os valores, neste tratamento, permaneceram entre 760 e $1017 \mathrm{~kg} / \mathrm{ha}$ de PV. A variação de $257 \mathrm{~kg} / \mathrm{ha} \mathrm{de}$ PV na CA durante o período de pastejo, verificada na DFA, minimiza o manejo animal no decorrer do ciclo da forrageira. Nos tratamentos DFB, DFBS e DFAS, por outro lado, a grande variação na $\mathrm{CA}$ foi mais bem representada pela equação cúbica. A relação cúbica e quadrática entre CA e dias de pastejo não é desejável no ponto de vista prático, pois a alternância de períodos com altas e baixas CA provoca intensificação do manejo na propriedade e prejudica o desempe-

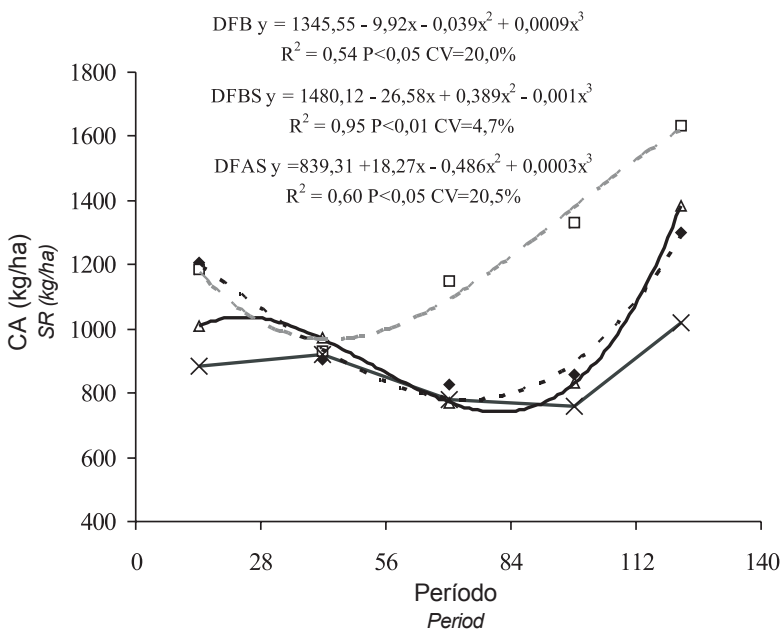
01/07-28/07 29/07-25/08 26/08/22/09 23/09-20/10 21/10-09/11
- DFB- valor médio observado
$\square \quad$ DFBS- valor médio observado
$\Delta \quad$ DFAS- valor médio observado
$\longrightarrow$ DFA- valor médio observado
- - DFBS- valor estimado

DFAS- valor estimado

- - - DFB-valor estimado

Figura 2 - Carga animal (CA) em pastagem de aveia preta $(A$. strigosa) + azevém (L. multiflorum) com disponibilidade de forragem baixa (DFB), disponibilidade de forragem alta (DFA), disponibilidade de forragem baixa + suplementação (DFBS) ou disponibilidade de forragem alta + suplementação (DFAS) na recria de novilhas de corte, de acordo com o período de pastejo.

Figure 2 - Stocking rate $(S R)$ in oat $(A$. strigosa) + Italian ryegrass (L. multiflorum) pasture with low forage availability (DFB), high forage availability (DFA), low forage availability + supplementation (DFBS) or high forage availability + supplementation (DFA) for rearing beef heifers, according to grazing period. 
nho dos animais que entram e saem constantemente da pastagem (Roso, 1998).

Nos períodos iniciais de utilização da pastagem, a combinação DFBS $\left(\mathrm{R}^{2}=0,95\right)$ indicou menor redução na $\mathrm{CA}$, em relação a $\mathrm{DFB}\left(\mathrm{R}^{2}=0,54\right)$. A elevada $\mathrm{CA}$ obtida no período inicial de pastejo na DFB não pôde ser mantida, provavelmente em função da baixa precipitação verificada no mês de agosto, que foi $50 \%$ inferior à média dos últimos 30 anos. O valor estimado pelas equações comprova a capacidade da suplementação de manter maior CA, mesmo em disponibilidades de forragem inferiores a $1.500 \mathrm{~kg} / \mathrm{ha}$ de MS e períodos de adversidades climáticas. Entre as vantagens de se investir na prática da suplementação, em relação ao uso exclusivo da pastagem, está o pequeno risco quanto ao fornecimento do suplemento, pois a quantidade oferecida é independente das condições climáticas (Pötter et al., 2000).

A CA, no decorrer do período de pastejo, apresentou comportamento semelhante em DFAS $\left(\mathrm{R}^{2}=0,601\right)$ e DFB $\left(\mathrm{R}^{2}=0,546\right)$. O uso de suplemento aos animais em DFAS manteve CA equivalente ao uso exclusivo da pastagem em DFB, com média de 969 e $1.003 \mathrm{~kg} /$ ha, respectivamente. A diferença média foi de $273 \mathrm{~kg} /$ ha de MS entre as MF estudadas. Portanto, quando o objetivo do manejo for explorar o uso de CA alta, torna-se economicamente mais vantajoso nestas condições, utilizar a pastagem com disponibilidade baixa (1.200 kg/ha de MS), uma vez que resulta em economia de $895 \mathrm{~kg}$ de suplemento durante o ciclo da pastagem.

A CA média verificada na DFBS foi semelhante à observada por Rocha et al. (2003a), $985 \mathrm{~kg} / \mathrm{ha}$ de $\mathrm{PV}$, com a mesma categoria animal, fornecendo suplemento aos animais, no período de julho ao final de setembro, na proporção de $1 \%$ do PV. A maior CA em DFB não interferiu na produção de forragem e, portanto, o uso de suplementos pode ser dispensado quando a MF da pastagem é de $1.200 \mathrm{~kg} / \mathrm{ha}$ de MS e o objetivo da utilização de aveia preta e azevém for a manutenção de alta carga animal.

O ganho de peso por área (GPA) não foi afetado pelas disponibilidades de forragem. A carga animal média para DFA e DFB foi de 871,1 e $1.019,7 \mathrm{~kg} / \mathrm{ha}$ de PV, respectivamente. O GMD, em todo o período de utilização da pastagem, foi de 0,536 kg para DFB, e $0,585 \mathrm{~kg}$, para DFA. Com uma diferença favorável na CA de apenas 148,6 kg de PV na DFB e GMD praticamente idêntico nas duas disponibilidades, não poderia ter havido diferença no GPA, que resulta da associação destas duas variáveis.

Para melhor avaliação do efeito da suplementação sobre o GPA, é necessário conhecer o efeito do uso do suplemento sobre o desempenho individual dos animais (Pilau et al., 2004). O GMD foi superior nas novilhas que receberam suplemento no primeiro, segundo, terceiro e quinto períodos de utilização da pastagem, com valores de 0,$623 ; 0,834 ; 1,000$ e 0,513 , nos animais suplementados, e de 0,$367 ; 0,642 ; 0,648 ; \mathrm{e} 0,260 \mathrm{~kg}$, nas novilhas em pastagem. No quarto período, não houve diferença no GMD entre novilhas PAST e PAST+SUPL, com média de $0,906 \mathrm{~kg} /$ animal $/$ dia. Na Tabela 2 , encontram-se os GPA observados, por período, e totais, para PAST e PAST+SUPL. A variação no GPA durante o período de pastejo entre PAST e PAST+SUPL seguiu a mesma tendência da variação no GMD, exceto no segundo período ( 29 de julho a 28 de agosto), em que o GPA também não diferiu, como no quarto período. No segundo período, houve menor aumento na CA (Figura 2), proporcionado pela suplementação, tanto na DFBS em relação a DFB como na DFAS em relação à DFA, de 2,7 e 5,8\%, respectivamente, não promovendo efeito da CA sobre o GPA. O efeito do GMD, nesta ocasião, não foi suficiente para elevar o GPA quando os animais foram suplementados.

Uma vez que o GPA é obtido pelo produto do GMD e do número de animais por dia, por hectare, as relações entre GMD, CA e período de pastejo podem potencializar ou prejudicar a produção animal total por área. O uso da suplementação possibilitou GPA total de $526 \mathrm{~kg} / \mathrm{ha}$, $59 \%$ superior ao obtido com uso exclusivo da pastagem, de $330 \mathrm{~kg} / \mathrm{ha}$. Estes valores são inferiores aos verificados por Frizzo et al. (2003), de $559 \mathrm{~kg} /$ ha para o nível de suplementação de $0,7 \%$ do $\mathrm{PV}$, e de $433 \mathrm{~kg} / \mathrm{ha}$, para novilhas exclusivamente em pastagem de aveia preta + azevém. Estes autores, entretanto, observaram aumento de apenas $29 \%$ no GPA proporcionado pela suplementação em relação à utilização exclusiva da pastagem, metade do incremento verificado neste experimento. Roso \& Restle (2000) observaram, com a mesma categoria animal em pastagem de aveia preta + azevém e um período de pastejo de 182 dias, GPA de $726 \mathrm{~kg} / \mathrm{ha}$ exclusivamente em pastejo contínuo. Quando se avalia GPA, portanto, torna-se importante considerar os efeitos ambientais referentes aos anos envolvidos, para se evitar frustrações quanto aos valores pretendidos no planejamento forrageiro. 
Tabela 2 - Ganho de peso por área $(\mathrm{kg} / \mathrm{ha})$ em pastagem de aveia preta $(A$. strigosa) + azevém $(L$. multiflorum) em duas disponibilidades de forragem, com ou sem suplementação para novilhas de corte em recria

Table 2 - Weight gain on oat (A. strigosa) + Italial ryegrass (L. multiflorum) pasture with two forage availability with or without supplementation for rearing beef heifers

\begin{tabular}{lcccccc}
\hline $\begin{array}{l}\text { Tratamento } \\
\text { Treatment }\end{array}$ & \multicolumn{5}{c}{$\begin{array}{c}\text { Período } \\
\text { Period }\end{array}$} & $\begin{array}{c}\text { Total } \\
\text { Total }\end{array}$ \\
\cline { 2 - 6 } & $01 / 07-28 / 07$ & $29 / 07-25 / 08$ & $26 / 08-22 / 09$ & $23 / 09-20 / 10$ & $21 / 10-09 / 11$ & \\
\hline DFB & 102 & 89 & 105 & 107 & 56 & 459 \\
DFA & 80 & 107 & 77 & 99 & 35 & 398 \\
\hline Past & $67 *$ & 82 & $60 * *$ & 92 & $29 *$ & $330^{*}$ \\
Past+supl. & $115^{*}$ & 113 & $120^{* *}$ & 115 & $63 *$ & $526^{*}$ \\
\hline Média & $91 \mathrm{a}$ & $97 \mathrm{a}$ & $92 \mathrm{a}$ & $103 \mathrm{a}$ & $46 \mathrm{~b}$ & 429 \\
Mean & & & & & & 21,75 \\
\hline $\mathrm{CV}$ & 17,28 & 28,09 & 25,07 & 21,95 & 44,05 & 2 \\
\hline
\end{tabular}

* na mesma coluna, diferem entre si $(P<0,05)$ (in the same column, differ $[P<0.05]$ ).

** na mesma coluna, diferem entre si $(P<0,01)$ (in the same column, differ $[P<0.01]$ ).

a, b na mesma linha diferem entre si $(P<0,01)(a, b$ in the same column, differ $[P<0.01])$.

DFA - disponibilidade de forragem alta, $1.500 \mathrm{~kg} / \mathrm{ha}$ de MS (DFA - high forage availability, 1,500 kg/ha DM).

DFB - disponibilidade de forragem baixa, $1.200 \mathrm{~kg} / \mathrm{ha}$ de MS (DFB - low forage availability, 1,200 kg/ha DM).

Past. - aveia preta + azevém sem suplementação (Past.- oat + annual ryegrass without supplement).

Past. + supl - aveia preta + azevém + 0,7\% do PV de grão de sorgo moído (Past. + suppl. - oat + annual ryegrass + 0.7\% BW sorghum grain)

\section{Conclusões}

A redução na massa de forragem de 1.500 para $1.200 \mathrm{~kg} / \mathrm{ha}$ de MS não altera a produção de forragem e o ganho de peso por área em pastagem de aveia preta + azevém. A suplementação aos animais, por sua vez, proporciona maior ganho de peso por área que o uso exclusivo da pastagem.

Menor disponibilidade de forragem de 1.500 para $1.200 \mathrm{~kg} / \mathrm{ha}$ de MS resulta em acréscimo na carga animal quando a menor disponibilidade for associada ao uso de suplemento aos animais.

Suplementação energética para animais em pastagem com disponibilidade de forragem de $1.500 \mathrm{~kg} / \mathrm{ha} \mathrm{de}$ MS corresponde, em carga animal, à utilização exclusiva da pastagem de aveia preta + azevém, com disponibilidade de forragem de $1.200 \mathrm{~kg} / \mathrm{ha}$ de MS.

\section{Literatura Citada}

AGUIAR, A.P.A. Possibilidades de intensificação do uso da pastagem através de rotação sem ou com uso mínimo de fertilizantes. In: SIMPÓSIO SOBRE MANEJO DE PASTAGEM, 14., 1999, Piracicaba. Anais... Piracicaba: Fundação de Estudos Agrários "Luiz de Queiroz", 1999. p.37-40.

BERETTA, V.; LOBATO, J.F.P. Sistema "um ano" de produção de carne: Avaliação de estratégias de alimentação hibernal de novilhas de reposição. Revista Brasileira de Zootecnia, v.27, n.1, p.157-163, 1998.

EMPRESA BRASILEIRA DE MPESQUISA E AGROPECUÁRIA - EMBRAPA. Centro Nacional de Pesquisa de Solos. Sistema brasileiro de classificação de solos. Brasília: EMBRAPA. Rio de Janeiro, 1999. 412p.
FREITAS, F.K.; ROCHA, M.G.; PILAU, A. et al. Dinâmica de uma pastagem de gramíneas temperadas sob duas disponibilidades de forragem. In: REUNIÃO ANUAL DA SOCIEDADE BRASILEIRA DE ZOOTECNIA, 39., 2002, Recife. Anais... Recife: Sociedade Brasileira de Zootecnia, 2002. CD-ROM. Forragicultura. FOR-1525.

FRIZZO, A.; ROCHA, M.G.; RESTLE, J. Suplementação energética na recria de bezerras de corte mantidas em pastagem de inverno. Revista Brasileira de Zootecnia, v.32, n.3, p.643-652, 2003.

HILLESHEIM, A. Fatores que afetam o consumo e perdas de capim-elefante (Penissetum purpureum, Schum) sob pastejo. Piracicaba: Escola Superior da Agricultura "Luiz de Queiroz”, 1997. 94p. Dissertação (Mestrado em Zootecnia) - Escola Superior da Agricultura "Luiz de Queiroz", 1997.

KLINGLMANN, D.L.; MILES, S.R.; MOTT, G.O. The cage method for determining consumption and yield of pasture herbage. Journal of Society of Agronomy, v.35, p.739746, 1943.

MORENO, J.A. Clima do Rio Grande do Sul. Porto Alegre: Secretaria da Agricultura, 1961. 41p.

NATIONAL RESEARCH COUNCIL - NRC. Nutrient requirement of beef cattle. 6.ed. Washington: National Academy Press, 1984. 90p.

PILAU, A.; ROCHA, M.G.; RESTLE, J. et al. Desenvolvimento de novilhas de corte recebendo ou não suplementação energética em pastagem hibernal sob diferentes disponibilidades de forragem. Revista Brasileira de Zootecnia, no prelo, 2005.

PHILLIPS, C.J.C. The use of conserved forages as a supplement for grazing dairy cows. Grass and Forage Science, v.43, n.1, p.215-230, 1988.

PÖTTER, L.; LOBATO, J.F.P.; MIELITZ NETTO, C.G.A. Análises econômicas de modelos de produção com novilhas de corte primíparas aos dois anos, três e quatro anos de idade. Revista Brasileira de Zootecnia, v.29, n.3, p.861-870, 2000.

REARTE, D.H.; PIERONI, G.A. Supplementation of temperate pastures. In: INTERNATIONAL GRASSLAND 
CONGRESS, 19., 2001, São Pedro. Preceedings... São Pedro: Sociedade Brasileira de Zootecnia, 2001. p.679-689.

RESTLE, J.; LUPATINI, G.C.; ROSO, C. et al. Eficiência e desempenho de categorias de bovinos de corte em pastagem cultivada. Revista Brasileira de Zootecnia, v.27, n.2, p.397-404, 1998.

ROCHA, M.G.; RESTLE, J.; PILAU, A. et al. Produção animal e retorno econômico da suplementação em pastagem de aveia preta e azevém. Ciência Rural, v.33, n.3, p.85-93, 2003 a.

ROCHA, M.G.; RESTLE, J.; FRIZZO, A. et al. Alternativas de utilização da pastagem hibernal para a recria de bezerras de corte. Revista Brasileira de Zootecnia, v.33, n.2, p.383392, 2003b.

ROSO, C. Produção animal em misturas de gramíneas anuais de estação fria. Santa Maria: Universidade Federal de Santa Maria, 1998. 104p. Dissertação (Mestrado em Zootecnia) - Universidade Federal de Santa Maria, 1998.

ROSO, C.; RESTLE, J. Aveia preta preta, triticale e centeio em mistura com azevém. 2. Produtividade animal e retorno econômico. Revista Brasileira de Zootecnia, v.29, n.1, p.85-93, 2000.
ROSO, C.; RESTLE, J.; SOARES, A.B. et al. Aveia preta preta, triticale e centeio em mistura com azevém. Dinâmica e qualidade de forragem. Revista Brasileira de Zootecnia, v.29, n.1, p.75-84, 2000.

STATISTICAL ANALYSES SYSTEM - SAS. SAS/STAT user's guide: statistics. 4.ed. Version 6, Cary: 1996. v.2, 943p.

SOARES, A.B.; RESTLE, J. Produção animal e qualidade de forragem de pastagem de triticale e azevém submetida a níveis de adubação nitrogenada. Revista Brasileira de Zootecnia, v.31, n.2, p.908-917, 2002 (suplemento).

WILM, H.G.; COSTELLO, D.F.; KLIPPLE, G.E. Estimating forage yield by the double-sampling methods. Journal of American Society of Agronomy, v.36, p.194-203, 1944.

Recebido em: 03/05/04

Aceito em: 10/03/05 